\title{
Fibrotic progression and radiologic correlation in matched lung samples from COVID-19 post-mortems
}

\author{
Emanuela Barisione ${ }^{1}$ (D) $\cdot$ Federica Grillo ${ }^{2,3}$ (D) Lorenzo Ball $^{3,4}$ (D) $\cdot$ Rita Bianchi $^{2} \cdot$ Marco Grosso $^{1} \cdot$ Patrizia Morbini $^{5}$ (D) \\ Paolo Pelosi ${ }^{3,4}$ - Nicolò Antonino Patroniti ${ }^{3,4}$ (1) Arduino De Lucia ${ }^{3}$ - Giovanni Orengo ${ }^{3}$ - Angelo Gratarola ${ }^{3}$. \\ Marta Verda ${ }^{6}$ (D) $\cdot$ Giuseppe Cittadini $^{7}$ (D) Luca Mastracci $^{2,3}$ (I) $\cdot$ Roberto Fiocca $^{2,3}$ (I)
}

Received: 11 June 2020 / Revised: 19 August 2020 / Accepted: 18 September 2020 / Published online: 28 September 2020

(C) The Author(s) 2020

\begin{abstract}
Data on the pathology of COVID-19 are scarce; available studies show diffuse alveolar damage; however, there is scarce information on the chronologic evolution of COVID-19 lung lesions. The primary aim of the study is to describe the chronology of lung pathologic changes in COVID-19 by using a post-mortem transbronchial lung cryobiopsy approach. Our secondary aim is to correlate the histologic findings with computed tomography patterns. SARS-CoV-2-positive patients, who died while intubated and mechanically ventilated, were enrolled. The procedure was performed $30 \mathrm{~min}$ after death, and all lung lobes sampled. Histopathologic analysis was performed on thirty-nine adequate samples from eight patients: two patients (illness duration $<14$ days) showed early/exudative phase diffuse alveolar damage, while the remaining 6 patients (median illness duration - 32 days) showed progressive histologic patterns ( 3 with mid/proliferative phase; 3 with late/fibrotic phase diffuse alveolar damage, one of which with honeycombing). Immunohistochemistry for SARS-CoV-2 nucleocapsid protein was positive predominantly in early-phase lesions. Histologic patterns and tomography categories were correlated: early/exudative phase was associated with ground-glass opacity, mid/proliferative lesions with crazy paving, while late/fibrous phase correlated with the consolidation pattern, more frequently seen in the lower/middle lobes. This study uses an innovative cryobiopsy approach for the post-mortem sampling of lung tissues from COVID-19 patients demonstrating the progression of fibrosis in time and correlation with computed tomography features. These findings may prove to be useful in the correct staging of disease, and this could have implications for treatment and patient follow-up.
\end{abstract}

Keywords Diffuse alveolar damage · COVID-19 $\cdot$ Lung fibrosis $\cdot$ Radiologic patterns $\cdot$ Transbronchial lung cryobiopsy

\section{Introduction}

In December 2019, a novel human coronavirus, the severe acute respiratory syndrome coronavirus-2 (SARS-CoV-2),

Emanuela Barisione, Federica Grillo and Lorenzo Ball contributed equally to this work.

Luca Mastracci

luca.mastracci@unige.it

1 Interventional Pulmonology Unit, Policlinico San Martino University Hospital, IRCCS for Oncology and Neuroscience, Genova, Italy

2 Anatomic Pathology Unit, Department of Surgical Science and Integrated Diagnostics (DISC), University of Genova, Genova, Italy

3 Policlinico San Martino University Hospital, IRCCS for Oncology and Neuroscience, Genova, Italy was identified in Wuhan, China [1], and, over the course of a few months, the resulting disease, now known as coronavirus disease 2019 (COVID-19), has spread worldwide, causing a global health emergency.

4 Anesthesia and Intensive Care Unit, Department of Surgical Science and Integrated Diagnostics (DISC), University of Genova, Genova, Italy

5 Unit of Pathology, University of Pavia and Fondazione IRCCS Policlinico San Matteo, Pavia, Italy

6 Radiology, Department of Health Sciences (DISSAL), University of Genova, Genova, Italy

7 General Radiology, Policlinico San Martino University Hospital, IRCCS for Oncology and Neuroscience, Genova, Italy 
The clinical presentation of COVID-19 ranges from asymptomatic infection to severe respiratory failure, with fever, fatigue and cough occurring in most cases. Rapid progression to severe respiratory distress requiring intubation and mechanical ventilation has been reported from 7 to $12 \%$ of patients (variable percentages in different countries) [2-4]. At imaging, bilateral interstitial pneumonia with characteristic ground-glass features is initially seen with associated crazy paving and consolidation patterns [5].

Data on the pathologic characteristics in COVID-19 are scarce, as post-mortems are infrequently carried out in consideration of the infectious hazard [6]. Indeed, complete postmortems have been strongly discouraged in some nations (e.g. in Italy, as airborne infection isolation autopsy roomsBSL3 - are not available in most hospitals), while other countries have developed guidelines (e.g. UK [7]) with in-depth recommendations and state that it is preferable, though not necessary, to have isolated BLS3 facilities. Presently, few case reports and series have described the lung pathology in cases of COVID-19 with tissue being sampled either from postmortem needle biopsies [8], from infection unsuspected surgical resection specimens [9], or from complete/in situ autopsies [10-12]. The descriptions available show diffuse alveolar damage (DAD) with exudates and a predominantly lymphocytic inflammatory infiltrate and large atypical pneumocytes. Pathological findings seem to overlap [13] with those seen in other coronavirus outbreaks, namely, in SARS (severe acute respiratory syndrome) $[14,15]$ and in MERS (Middle East respiratory syndrome) [16].

In our academic hospital, a specialized multidisciplinary team including lung and intensive care physicians, radiologists, as well as specialized pathologists, with particular expertise in transbronchial lung cryobiopsies (TBLCs) has been routinely performing TBLCs for interstitial lung diseases and has collected considerable experience in over 100 procedures [17]. TBLCs are an innovative procedure which permits the bronchoscopic sampling of lung parenchyma using specialized cryoprobes, which, by rapidly freezing the bronchial wall and adjacent lung parenchyma, enable the operator to sample multiple areas of the lung and obtain biopsies of about 5-6 $\mathrm{mm}$ in diameter [18].

Considering (1) the need to follow recommendations which discourage complete post-mortems, (2) the available local expertise (both in terms of TBLC procedure and specialized lung pathology and radiology evaluation) and (3) the interest in obtaining histomorphologic information, a cryobiopsy-based limited post-mortem procedure has been implemented since the 10th of April 2020. The primary aim of the present study was to describe the chronology of lung pathological changes in COVID-19 by using post-mortem (pm) TBLC, in mechanically ventilated patients who died in the intensive care unit (ICU). Our secondary aim was to relate the morphologic findings with computed tomography (CT) imaging patterns.

\section{Materials and methods}

\section{Patient inclusion criteria}

ICU patients who died while intubated and mechanically ventilated with interstitial pneumonia on $\mathrm{CT}$ scan and positive polymerase chain reaction for SARS-Cov-2 (either on nasopharyngeal swab or broncho-alveolar lavage) were enrolled. Death was ascertained by a continuous 20-minutes flat electrocardiogram; consent was verbally obtained from the next of kin, and procedure was initiated within $30 \mathrm{~min}$. The protocol was approved by the regional ethics committee (reference number: CER Liguria: 144/2020-DB id 10460 on the $06 / 04 /$ 2020).

\section{Post-mortem trans-bronchial lung cryobiopsy (pmTBLC) procedure}

The methodology described for pmTBLC is slightly different compared with in vivo TBLC; though perhaps inappropriate, the term cryobiopsy (and not cryosample as would be more fitting in the deceased) is used throughout as it refers more to the procedure than the sample itself. All patients were already intubated and mechanically ventilated with an endotracheal tube. At death, heparin infusion was immediately stopped, and subsequently a single-use, flexible video-bronchoscope (AmbußaScope ${ }^{\mathrm{TM}}$, Ambu A/S, Ballerup, Denmark) with a 2.6-mm-wide operative channel was introduced. A $1.7-\mathrm{mm}$ wide cryoprobe (ErbeCryo®, Erbe Elektromedizin GmbH, Tuebingen, Germany) was inserted within the working channel, and the cryoprobe was then frozen for approximately 10 $11 \mathrm{~s}$ and biopsy performed.

The sampling protocol included 2 biopsies at each site starting from the right lower lobe (RLL) and continuing to the right middle lobe (RML), right upper lobe (RUL), left lower lobe (LLL) and left upper lobe (LUL). A maximum of 10 biopsies were collected and immediately fixed in $10 \%$ buffered formalin.

During all procedures, operators wore full protective equipment including whole body suits, protective hoods, moulded protection masks (FFP3), visors, goggles and double-layer gloves. No operator infection occurred.

\section{Clinical details and imaging}

All significant clinical details were collected for each patient including days from symptom onset, days from arrival in emergency, days of ICU from start of mechanical ventilation, symptoms at presentation, known pre-existing conditions (e.g. 
hypertension, diabetes, lung disease, heart disease), treatment, tracheotomy, known super-infection and clinical cause of death.

All patients had undergone high-resolution multi-detector CT imaging scans (Siemens Definition Flash, 128 slice, Erlangen, Germany). CT scan evaluation was performed by two experienced radiologists (GC and MV), and the identified patterns were placed in the following categories: ground-glass opacity (GGO), crazy paving (CP), consolidation (C) and honeycombing $(\mathrm{HC})$ according to pulmonary lobes $[5,19$, 20].

\section{Processing of pmTBLC samples}

All procedures followed strict guidelines to minimize risk of infection. Samples were formalin fixed (10\% buffered formalin) for a minimum of $24 \mathrm{~h}$, and then, tissue was routinely processed and paraffin embedded. From the paraffin blocks, 3-4- $\mu \mathrm{m}$-thick sections were cut and stained with haematoxylin and eosin (H\&E). Immunostaining (cytokeratin 7, CD3, CD20, CD31, CD61, CD68, CD163, p40, TTF1 and smooth muscle actin) was performed on the Ventana BenchMark ULTRA (Ventana Roche Diagnostics, Basel, Switzerland) automated immunostainer as per manufacturer instructions. Mallory's trichrome (for connective tissue) and alcian blue-PAS (for mucins) stain were performed on the BenchMark Special stains Roche automated stainer as per manufacturer instructions. Double immunohistochemical staining was obtained by developing reactions in brown using UltraView Universal DAB Detection Kit and in red using UltraView Universal Alkaline Phosphatase Red Detection Kit, while double CK7/trichrome staining was obtained by firstly performing immunohistochemistry.

\section{Histopathologic evaluation of pmTBLC samples}

Adequacy was evaluated by considering dimensions of the samples ( $\mathrm{mm}$ on both axes), surface area $\left(\mathrm{mm}^{2}\right)$ and percentage of lung parenchyma present in each biopsy (at least 30\%) [21]. Adequate samples were classified as centrally sampled when predominant bronchi with cartilage plates or bronchiolar structures were seen in more than $40 \%$ of surface or peripherally sampled when alveoli were present in at least $60 \%$ of surface with or without visceral pleura [22].

All samples were evaluated simultaneously by a panel of experienced pathologists. Histologic elementary lesions (pneumocyte loss with discontinuation of alveolar epithelial lining, hyaline membranes, intra-alveolar fibrinous exudate, early fibroblastic interstitial fibrosis, obliteration of the alveolar structure by fibrosis, type 2 pneumocyte hyperplasia and atypia, Mallory-like intracytoplasmic inclusions in type 2 pneumocytes, micro-honeycombing, foci of bronchopneumonia) were searched separately in all available biopsies and scored as 0 absent, 1 mild and 2 marked. Inflammation was also scored as absent (score 0), mild (score 1) or marked (score 2), and immunohistochemistry was used to distinguish $\mathrm{T}$ lymphocytes (CD3+ ), B lymphocytes (CD20+) and alveolar macrophages (CD68+, CD163+). CD61 was used for the detection of platelet microthrombi and megakaryocytes in all adequate samples [23].

On the basis of the overall expression of the above elementary lesions, one of the following histologic patterns for DAD was assigned to each biopsy site: early exudative phase, mid proliferative phase and late/organizing fibrotic phase with or without honeycombing [24]. A comprehensive pattern assignment, for each patient, was based on the predominant lesions observed as a complete evaluation of all available biopsies. We must underline, however, that pattern recognition is not clear-cut and various patterns may be seen at different sites in the same patient. Indeed, such patterns were assigned taking into account the most represented lesions and not only the worst (when minimal). Histologic patterns were also correlated with biopsy site (upper, middle or lower lobes).

Immunohistochemistry for SARS-CoV-2 was performed on all available samples using an antibody directed against the nucleocapsid protein (rabbit monoclonal antinucleocapsid protein, Sino Biological Inc., Chesterbrook, PA, USA), and immunoexpression was evaluated with regard to site (bronchial mucosa, pneumocytes, macrophages, hyaline membranes) and intensity of positivity (score $0-2$ where 0 is absent, 1 is mild, 2 is intense) [25, 26]. SARS-CoV-2positive and SARS-CoV-2-negative controls were used.

\section{Statistical analysis}

Histologic patterns were correlated with radiologic categories by Spearman's Rho analysis using commercial statistical software (Statistical Package for Social Science, SPSS) and expressed as $r_{\mathrm{s}}$ where total concordance is 1 .

\section{Results}

\section{Patient characteristics}

Eight patients were included in the study between the 16th of April and the 4th of May 2020. Patients' median age was 76 years (range 47-79 years); 2 were female and 6 were male. Median time of symptom onset was 5 days prior to hospitalization (range 1-7 days), while admission to ICU and mechanical ventilation was on average 8 days after hospitalization (range 1-18 days). Median stay in ICU was 14 days before death (range 1-29 days). Two patients died from coincidental causes: patient 6 died from haemorrhagic shock following surgery; patient 8 died from cardiogenic shock due to acute myocardial infarction. Patient characteristics are shown in Table 1. All patients, except for patients 1 and 6 , had been 
Table 1 Clinical characteristics of patients with fatal COVID-19

\begin{tabular}{|c|c|c|c|c|c|c|c|c|c|}
\hline Patient & $\begin{array}{l}\text { Gender } \\
\text { (male/female) }\end{array}$ & $\begin{array}{l}\text { Age } \\
\text { (years) }\end{array}$ & $\begin{array}{l}\text { Clinical cause } \\
\text { of death }\end{array}$ & Symptoms & $\begin{array}{l}\text { Days from } \\
\text { symptom } \\
\text { onset to } \\
\text { death }\end{array}$ & $\begin{array}{l}\text { Days from } \\
\text { hospitalization } \\
\text { to death }\end{array}$ & $\begin{array}{l}\text { Days from } \\
\text { ICU } \\
\text { admission } \\
\text { to death }\end{array}$ & $\begin{array}{l}\text { Pre-existing } \\
\text { conditions }\end{array}$ & Specific treatment \\
\hline 1 & M & 75 & $\begin{array}{l}\text { Refractory } \\
\text { hypoxemia }\end{array}$ & $\begin{array}{l}\text { Fever, } \\
\text { tachypnoea }\end{array}$ & 33 & 26 & 17 & $\begin{array}{l}\text { HPT, } \\
\text { ischemic } \\
\text { heart } \\
\text { disease }\end{array}$ & $\begin{array}{l}\text { Tocilizumab, } \\
\text { hydroxychloroquine, } \\
\text { methylprednisolone }\end{array}$ \\
\hline 2 & $\mathrm{~F}$ & 76 & $\begin{array}{l}\text { Massive } \\
\text { pulmonary } \\
\text { embolism }\end{array}$ & $\begin{array}{l}\text { Fever, } \\
\text { dyspnoea }\end{array}$ & 24 & 17 & 9 & None & $\begin{array}{l}\text { Tocilizumab, } \\
\text { hydroxychloroquine, } \\
\text { methylprednisolone }\end{array}$ \\
\hline 3 & M & 78 & $\begin{array}{l}\text { Cardiogenic } \\
\text { shock }\end{array}$ & $\begin{array}{l}\text { Fever, dry } \\
\text { cough }\end{array}$ & 42 & 35 & 17 & HPT & $\begin{array}{l}\text { Darunavir/ritonavir, } \\
\text { hydroxychloroquine, } \\
\text { oseltamivir, } \\
\text { tocilizumab, } \\
\text { methylprednisolone }\end{array}$ \\
\hline 4 & M & 59 & $\begin{array}{l}\text { Refractory } \\
\text { hypoxemia }\end{array}$ & $\begin{array}{l}\text { Fever, } \\
\quad \text { lipothymia }\end{array}$ & 31 & 30 & 29 & DM (type II) & $\begin{array}{l}\text { Darunavir/ritonavir, } \\
\text { hydroxychloroquine, } \\
\text { methylprednisolone }\end{array}$ \\
\hline 5 & M & 79 & $\begin{array}{l}\text { Refractory } \\
\text { hypoxemia }\end{array}$ & $\begin{array}{l}\text { Fever, } \\
\text { dyspnoea }\end{array}$ & 20 & 16 & 11 & HPT & $\begin{array}{l}\text { Hydroxychloroquine, } \\
\text { methylprednisolone }\end{array}$ \\
\hline 6 & $\mathrm{~F}$ & 77 & $\begin{array}{l}\text { Haemorrhagic } \\
\text { shock }\end{array}$ & Asymptomatic & $5 *$ & 4 & 4 & HPT & None \\
\hline 7 & M & 69 & $\begin{array}{l}\text { Refractory } \\
\text { hypoxemia }\end{array}$ & $\begin{array}{l}\text { Fever, dry } \\
\text { cough }\end{array}$ & 38 & 33 & 19 & None & $\begin{array}{l}\text { Darunavir/ritonavir, } \\
\text { hydroxychloroquine, } \\
\text { methylprednisolone }\end{array}$ \\
\hline 8 & M & 47 & $\begin{array}{l}\text { Cardiogenic } \\
\text { shock }\end{array}$ & $\begin{array}{l}\text { Fever, } \\
\text { dyspnoea }\end{array}$ & 14 & 9 & 1 & $\begin{array}{l}\text { HPT, } \\
\text { ischemic } \\
\text { heart } \\
\text { disease, } \\
\text { kidney } \\
\text { transplant }\end{array}$ & Methylprednisolone \\
\hline
\end{tabular}

ICU intensive care unit, HPT hypertension, DM diabetes mellitus

*Patient was asymptomatic and time refers from positive viral PCR

on non-invasive continuous positive airway pressure before intubation, and all received anti-coagulation treatment and systemic antibiotics/antimycotics.

\section{Biopsy adequacy}

Comprehensively, 63 pmTBLCs (median eight per patient, range 6-10) were collected from eight patients; the mean diameter was $6.8 \mathrm{~mm}$ in maximum axis and 4.25 in minimum axis and mean surface area was $29.5 \mathrm{~mm}^{2}$. Thirty-nine samples were considered adequate, and for each sample site, one or two samples were available for evaluation depending on adequacy. A rather gradual learning curve was necessary to reach a sufficient number of adequate samples (for the first 4 patients, a median of 7 biopsies, of which only a median of 2 adequate biopsies were obtained, while for the following 4 patients, a median of 9 biopsies of which a median of 8 adequate biopsies were obtained) as the technique is slightly different in this setting compared with living patients. Indeed, the fact that patients were intubated and mechanically ventilated as well as the unavailability of a fluoroscope for guidance in ICU required an initial modification of the pmTBLC approach. Of the adequate biopsies, 7 were considered centrally sampled while 32 were peripherally sampled.

\section{Lung histology on pmTBLC}

Elementary lesions for each patient were evaluated and findings are summarized in Table 2. Other, less frequent, histologic lesions were squamous metaplasia and alveolar bronchiolization, only seen in patient 1 .

Common features were type II pneumocyte hyperplasia, atypical pneumocytes with occasional multi-nucleation and intracytoplasmic eosinophilic Mallory-like inclusions in type 2 pneumocytes suggestive of proteasome dysfunction (Fig. 1).

Inflammation was generally mild and predominantly composed of macrophages and $\mathrm{CD} 3+\mathrm{T}$ lymphocytes, while $\mathrm{B}$ cells were only observed in sparse aggregates. Macrophages 


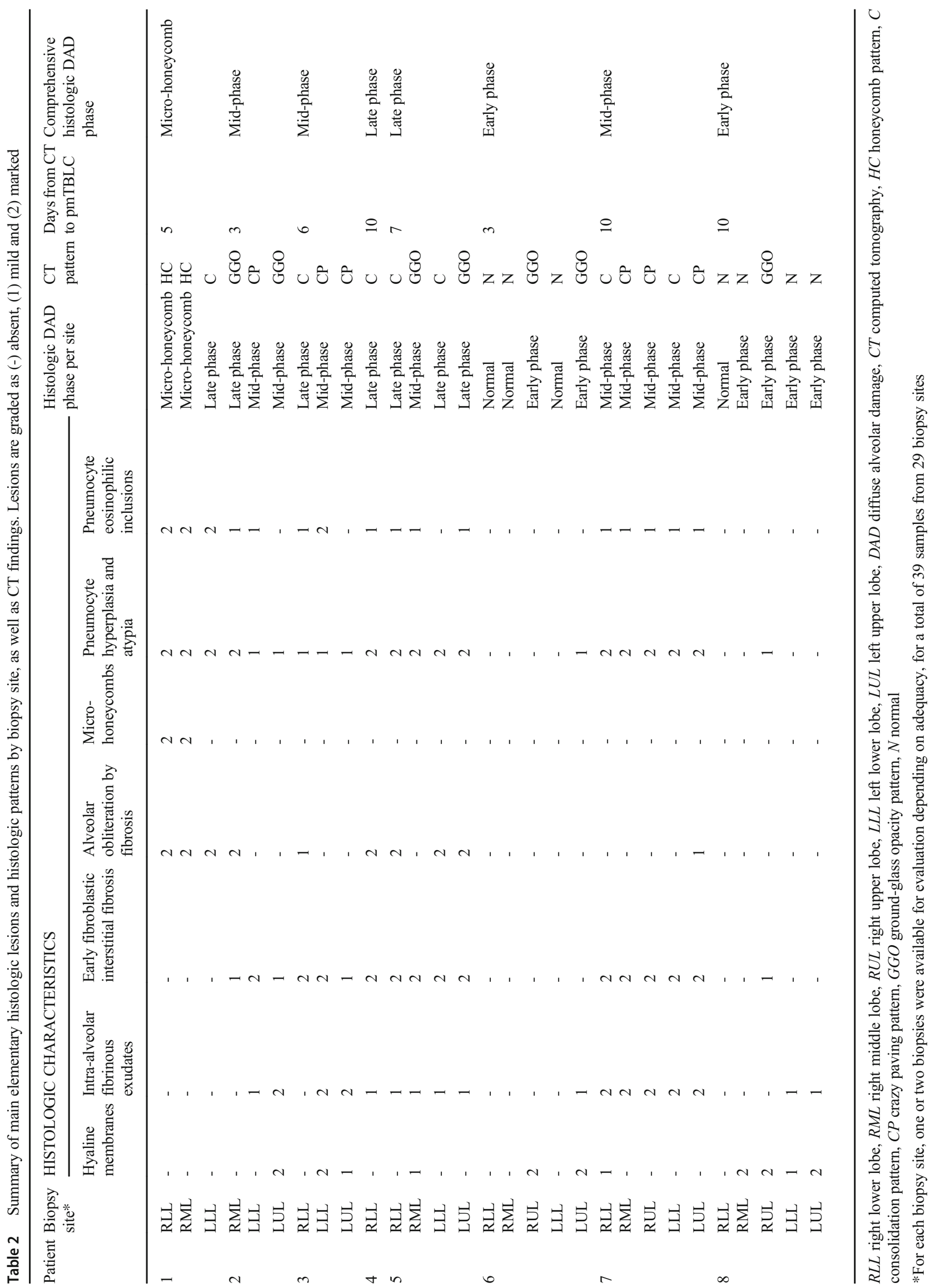


Fig. 1 Elementary lesions commonly seen in the organizing phase of DAD: a Hyperplastic type II pneumocytes line an alveolus inside which an aggregate of macrophages can be seen $(H \& E, \times 60$; scale bar 50 $\mu \mathrm{m})$; b atypical pneumocytes with occasional multi-nucleation line a residual alveolar lumen surrounded by early fibrosis (H\&E, $\times 60$; scale bar $50 \mu \mathrm{m})$. c Intracytoplasmic eosinophilic Mallory-like inclusions in type 2 pneumocytes covering alveolar residues surrounded by fibroblastic fibrosis $(\mathrm{H} \& \mathrm{E}, \times 60$; scale bar $50 \mu \mathrm{m})$. d Fibroblastic foci (arrowheads) are characteristic of the late/ organizing phase of DAD and associated with complete derangement/obliteration of alveolar structure $(\mathrm{H} \& \mathrm{E}, \times 40$; scale bar $50 \mu \mathrm{m})$. e CD61 immuno-stained section showing a platelet microthrombus in a small-sized vessel $(\mathrm{CD} 61, \times 20$; scale bar $50 \mu \mathrm{m})$. f Interstitial proliferation of smooth muscle fibres (red) in a microhoneycombing area; CK7 highlights the bronchiolization of the alveolar epithelium (CK7 immunoperoxidase with Mallory trichrome counterstain, $\times 20$; scale bar $50 \mu \mathrm{m})$

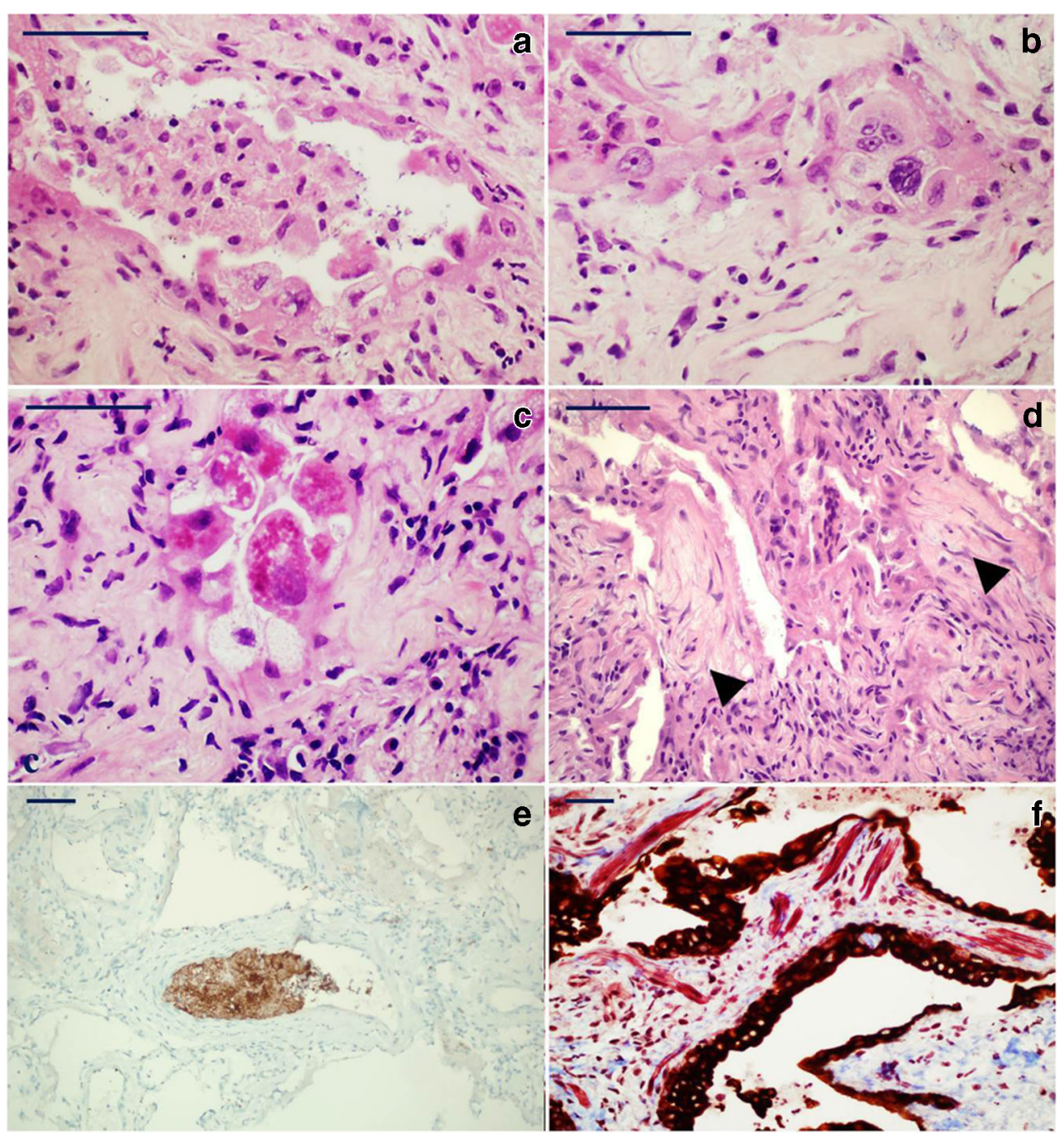

(CD163+, CD68+) were the main inflammatory cell type often associated with intra-alveolar fibrinous exudates. Neutrophilic infiltrates were mild, except for patient 7 who showed diffuse bronchopneumonic neutrophilic inflammation and tested positive for Pseudomonas aeruginosa at bronchoalveolar lavage.

With regard to vascular injury, platelet microthrombi were identified using CD61 in 4 patients (patient 2, 6,7 and 8) both as small capillary thrombi and as one organized thrombus in a small vessel (Fig. 1). Following the report of endotheliitis present in COVID-19 patients [27, 28], this feature was also actively looked for but to no avail.

The following comprehensive histologic diagnostic patterns (see table 2) could be distinguished:

Early exudative DAD phase in two patients-patients $6(5$ days from positive PCR, though asymptomatic) and 8 (14 days of duration from symptom onset): this pattern of injury was characterized by alveolar pneumocyte denudation with intra-alveolar hyaline membrane formation in the absence of interstitial fibrosis or alveolar structure obliteration (Fig. 2).
Patient 6 died while asymptomatic but with SARS-CoV-2 infection detected on preoperative swab (surgery was for acute gastric haemorrhage due to invasive cancer), showing just focal presence of hyaline membranes in the upper lobe biopsies. The upper and middle lobe biopsies of patient 8 also showed similar changes.

Patterns of increasing severity of parenchymal involvement (median day of duration from symptom onset: 32 days, range 20-42 days) were as follows:

Mid proliferative phase DAD in 3 patients-patients 2, 3 and 7: the main features consisted in marked intra-alveolar fibrinous exudates, filling and expanding alveoli, frequently associated with numerous intra-alveolar macrophages (Fig. 3). These findings were frequently associated with mild fibroblastic fibrosis, with no evidence of mature collagen deposition. Signs of mural incorporation of the intra-alveolar fibrinous exudate and occasional organizing pneumonia-like fibroblastic plugs filling some alveoli and bronchioles were observed.

Late/organizing fibrotic phase of DAD in 2 patientspatients 4 and 5: features of organization/repair were 
Fig. 2 Histology and radiology of early diffuse alveolar damage (DAD) pattern: a CK7 highlights the continuity of the alveolar epithelial lining in an unaffected area (CK7 immunoperoxidase, $\times$ 60; scale bar $30 \mu \mathrm{m})$. b Loss of the alveolar epithelium (black arrowheads) is accompanied by the appearance of hyaline membranes (red arrowhead) (CK7 immunoperoxidase, $\times 60$; scale bar $30 \mu \mathrm{m})$. c Intra-alveolar hyaline membranes in the absence of interstitial fibrosis and alveolar distortion $(\mathrm{H} \& \mathrm{E}, \times 20$; scale bar $50 \mu \mathrm{m})$. d CT findings of diffuse bilateral ground-glass opacities (red arrowheads) defined as hazy, increased opacity of lung, with preservation of bronchial and vascular margins. Normal lung for comparison is identified by green asterisk

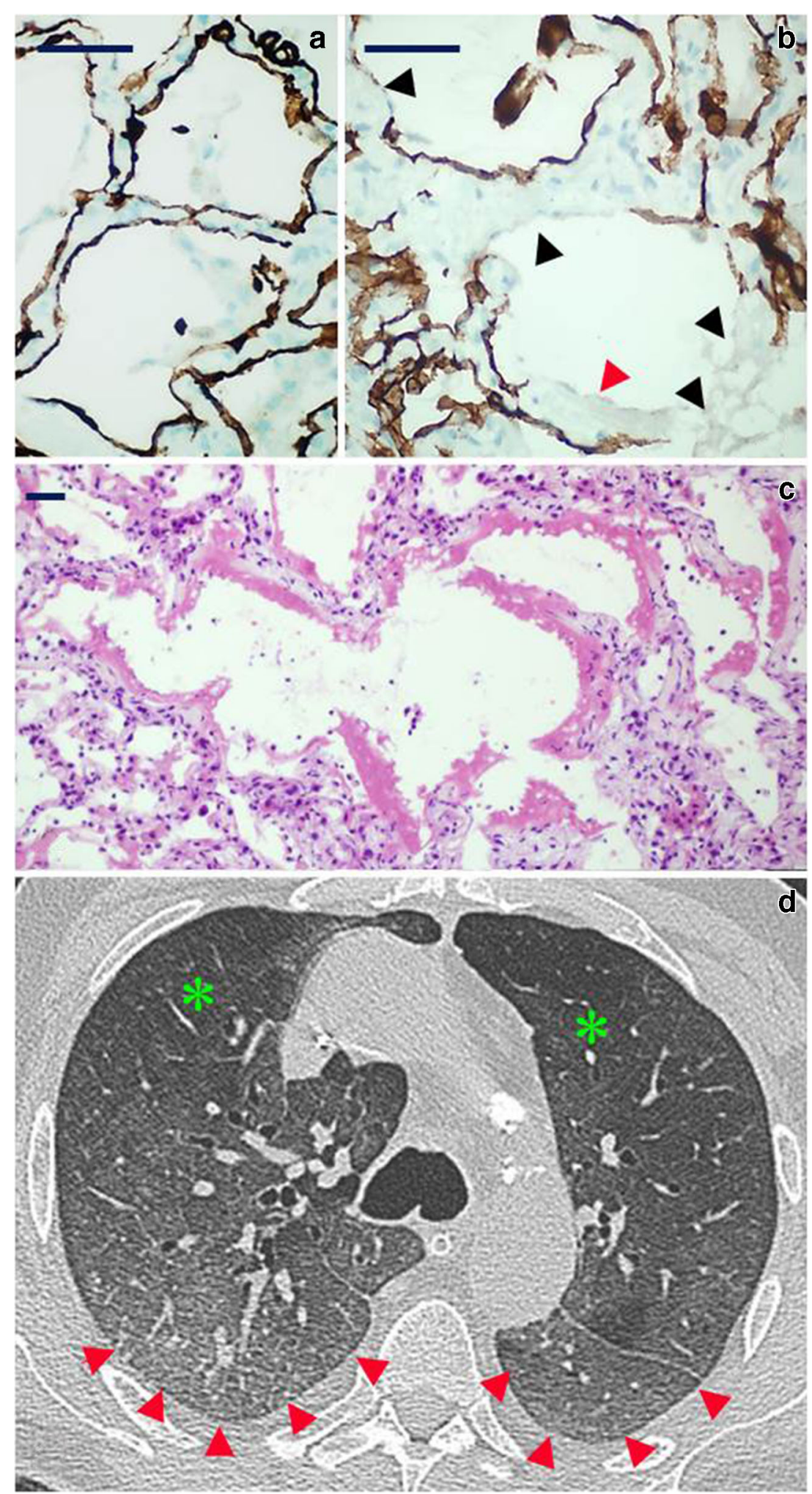

characterized by complete derangement/obliteration of alveolar structure by progressive interstitial fibroblast proliferation with sparse collagen fibre deposition. Alveoli were only readily seen by CK7 immunostaining as they become slit-like and compressed by fibrosis (Fig. 4).
Latelorganizing fibrotic phase of DAD with microhoneycombing was seen in patient 1 (Fig. 5) characterized by structure re-modelling and bronchiolar metaplasia of remanaged alveoli. Mature collagen, interstitial smooth muscle fibres and squamous metaplasia were also seen in this case. 


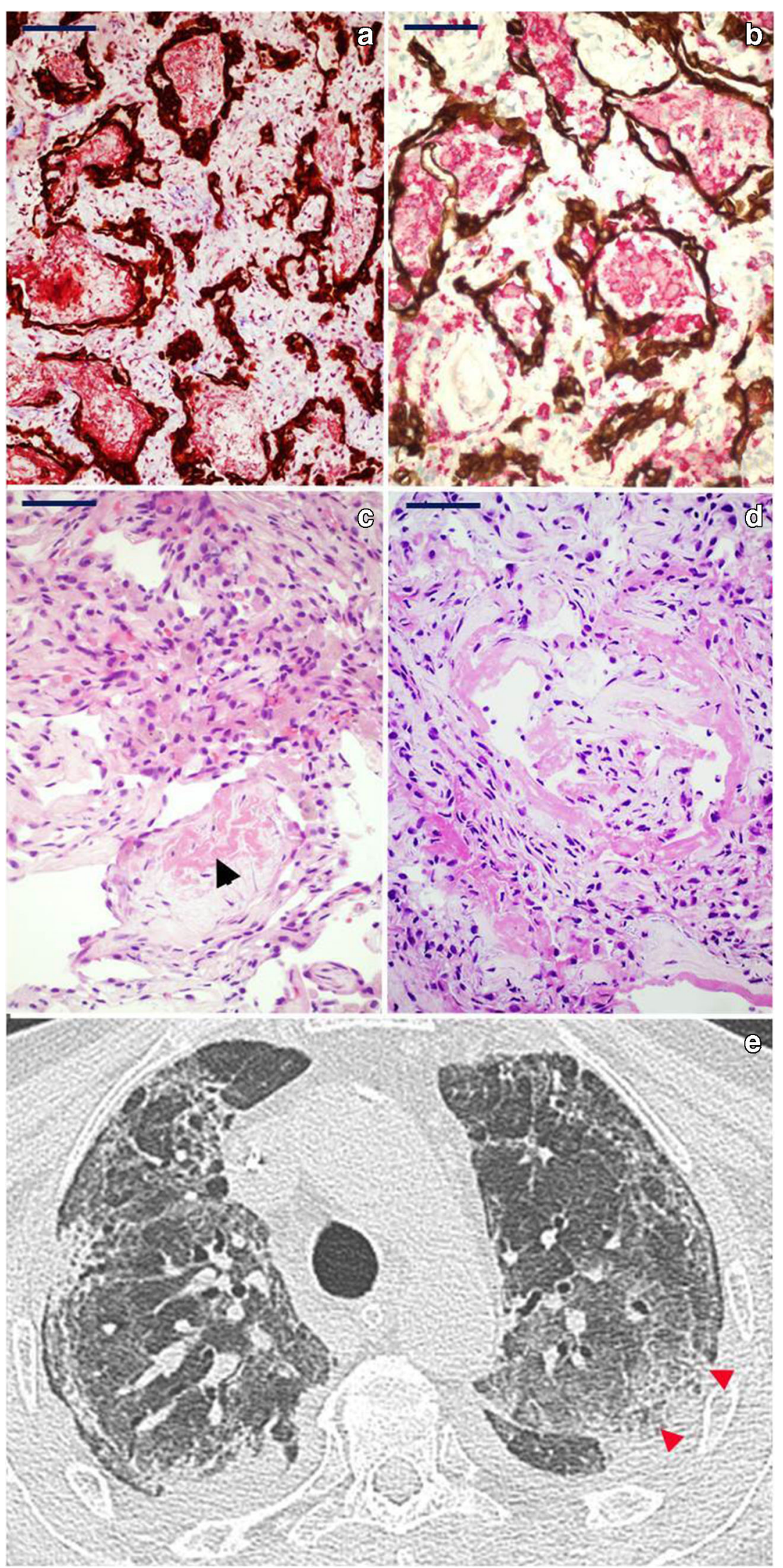


Fig. 3 Histology and radiology of mid-phase DAD pattern: a CK7 and Mallory trichrome, respectively, highlight marked intra-alveolar fibrinous exudates (red) and hyperplasia of the epithelial lining (brown) (CK7 immunoperoxidase and Mallory trichrome counterstain, $\times 40$; scale bar $50 \mu \mathrm{m})$. b Numerous intra-alveolar macrophages are stained by CD163 (red), while CK7 highlights the epithelial lining (brown); also note the interstitial thickening (CK7 immunoperoxidase and CD163 alkaline phosphatase red; $\times 40$; scale bar $50 \mu \mathrm{m})$. $\mathbf{c}$ Mural incorporation of the intra-alveolar fibrinous exudate (arrowhead) $(\mathrm{H} \& \mathrm{E}, \times 40$; scale bar 50 $\mu \mathrm{m})$. d Intra-alveolar organization of hyaline membrane residues with organizing pneumonia (OP)-like pattern $(\mathrm{H} \& \mathrm{E}, \times 40$; scale bar $50 \mu \mathrm{m})$. e CT showing a "crazy paving" pattern (red arrowheads), characterized by thickened interlobular septa and intralobular lines superimposed on a background of GGO resembling irregularly shaped paving stones. Peripheral fibrotic bands and traction bronchiolectasia are also present

Histologic patterns were correlated with biopsy sites showing that early exudative lesions were more frequently found in the upper lobes, while mid- and late-phase patterns were predominantly observed in the lower/middle lobes (Fig. 6).

Pleura with mesothelium was seen in 7 patients (15 samples). Mesothelium appeared either normal or reactive and hyperplastic and the latter were seen in 13 samples from 7 patients, 4 of which also showed inflammation with fibrin deposition.

\section{Immunohistochemistry for nucleocapsid protein of SARS-CoV-2}

Positive staining for anti-nucleocapsid SARS-CoV-2 protein was clearly present in patients 6 and 8 with early exudative phase lesions. Staining was diffuse and intensely positive in hyaline membranes, pneumocytes and macrophages as well as scattered positive bronchial cells with a positive cytoplasm and luminal rim (Fig. 7). All other patients, with midproliferative and late/organizing fibrotic phase, did not show staining in macrophages or pneumocytes except for faint staining in residual foci of exudative lesions.

\section{Correlation between lung histologic patterns and radiology findings}

CT scans were performed within 5 days prior to death for all patients except for patient 4 , patient 7 and patient 8 whose last CT scan was 10 days before death (median between CT and death 6 days, range 1-10) but was re-assessed by chest X-rays within the last 3 days from death.

As shown in Table 3 and Fig. 8, sites with normal CT findings corresponded to normal histology in 4 sites and early exudative phase DAD in 3 out of 7 sample sites. Sites with GGO at CT showed a mixture of patterns ranging from early to mid to late phases ( $3 / 7$ versus $2 / 7$ versus $2 / 7$, respectively), while areas of $\mathrm{CP}$ all corresponded to mid proliferative phase histologic patterns (6 sample sites). Finally consolidation at
CT correlated with 2 mid-phase and 5 late/organizing-phase sites out of 7 . The only 2 biopsy sites with microhoneycombing at histology came from the same patient who showed marked consolidation, calcifications and honeycombing at imaging. Comprehensively, histology patterns and CT categories showed significant correlation $\left(\mathrm{r}_{\mathrm{s}}=0\right.$. 84 ) in the 29 biopsy sites evaluated.

\section{Discussion}

In this study, the post-mortem transbronchial lung cryobiopsy technique permitted sampling of different lung lobes in 8 mechanically ventilated SARS-CoV-2-positive patients. The main findings of this study include the following: (1) the identification of a chronological evolution of lesions from an early exudative phase with hyaline membranes to a mid-phase characterized by intra-alveolar fibrinous exudate and early fibroblastic interstitial fibrosis to a late phase with alveolar obliteration by fibrosis and possible micro-honeycombing; (2) mild degree of inflammatory infiltrates; and (3) correlation of histologic patterns with lung CT alterations.

To our knowledge, this is the first study which uses the innovative approach of post-mortem transbronchial lung cryobiopsy for tissue collection. Though sampling bias should definitely be kept in mind, the cryobiopsy technique permits relatively large biopsy samples (mean of nearly $30 \mathrm{~mm}^{2}$ ) obtained from ventilated lungs just $30 \mathrm{~min}$ after death with nearly no crush artefacts on fresh samples [21] in a protected environment for the operator. A further advantage is that the operator identifies precisely the bronchus from which the surrounding lung parenchyma is obtained making radiological correlation extremely accurate. Similar comparable histologic findings are absent in living patients, making it impossible to understand in vivo pathological evolution.

Most of our patients showed variable severity of fibrosis, from early interstitial to severe obliteration of alveolar structure with organizing predominant features. Previous histologic reports have described bilateral DAD with intra-alveolar exudates, hyaline membrane formation, pneumocyte hyperplasia/atypia and loss with desquamation, as well as other early changes such as alveolar oedema and proteinaceous exudates, with major inflammatory infiltration $[8,9,12]$, possible consolidation with fibroblastic proliferation [10, 29], and/or pulmonary thromboemboli $[11,30]$. The increased fibrosis, reported in our patients compared with the previous studies, may be explained by different factors including general medical treatment, by the duration of mechanical ventilation or by the evolution of disease towards fibrotic phases. In our study, the duration of symptoms before death was longer than 20 days in all but two patients, with a maximum of 42 days, compared with other studies in which mean length of disease was just 5 to 7 days $[10,12]$. Our data suggest that 
Fig. 4 Histology and radiology of late/organizing phase of DAD pattern: aspects of progressive derangement/obliteration of alveolar structure by interstitial fibroblast proliferation. a-b Alveoli are still recognizable although distorted $(\mathbf{a}, \mathrm{H} \& \mathrm{E}, \times 20$; b, CK7 immunoperoxidase with Mallory trichrome counterstain, $\times$ 20; scale bar $50 \mu \mathrm{m})$. c-d Alveoli become slit-like and compressed by fibrosis and are only readily seen by CK 7 immunostaining (c, $\mathrm{H} \& \mathrm{E}, \times 20 ; \mathbf{d}, \mathrm{CK} 7$

immunoperoxidase with Mallory trichrome counterstain, $\times 20$; scale bar $50 \mu \mathrm{m})$. e CT shows advanced parenchymal alterations with predominant dorsal consolidations (homogeneous increase in pulmonary parenchymal attenuation that obscures the margins of vessels and airway walls as opposed to GGO — red asterisks); peripheral crazy paving pattern is seen anteriorly

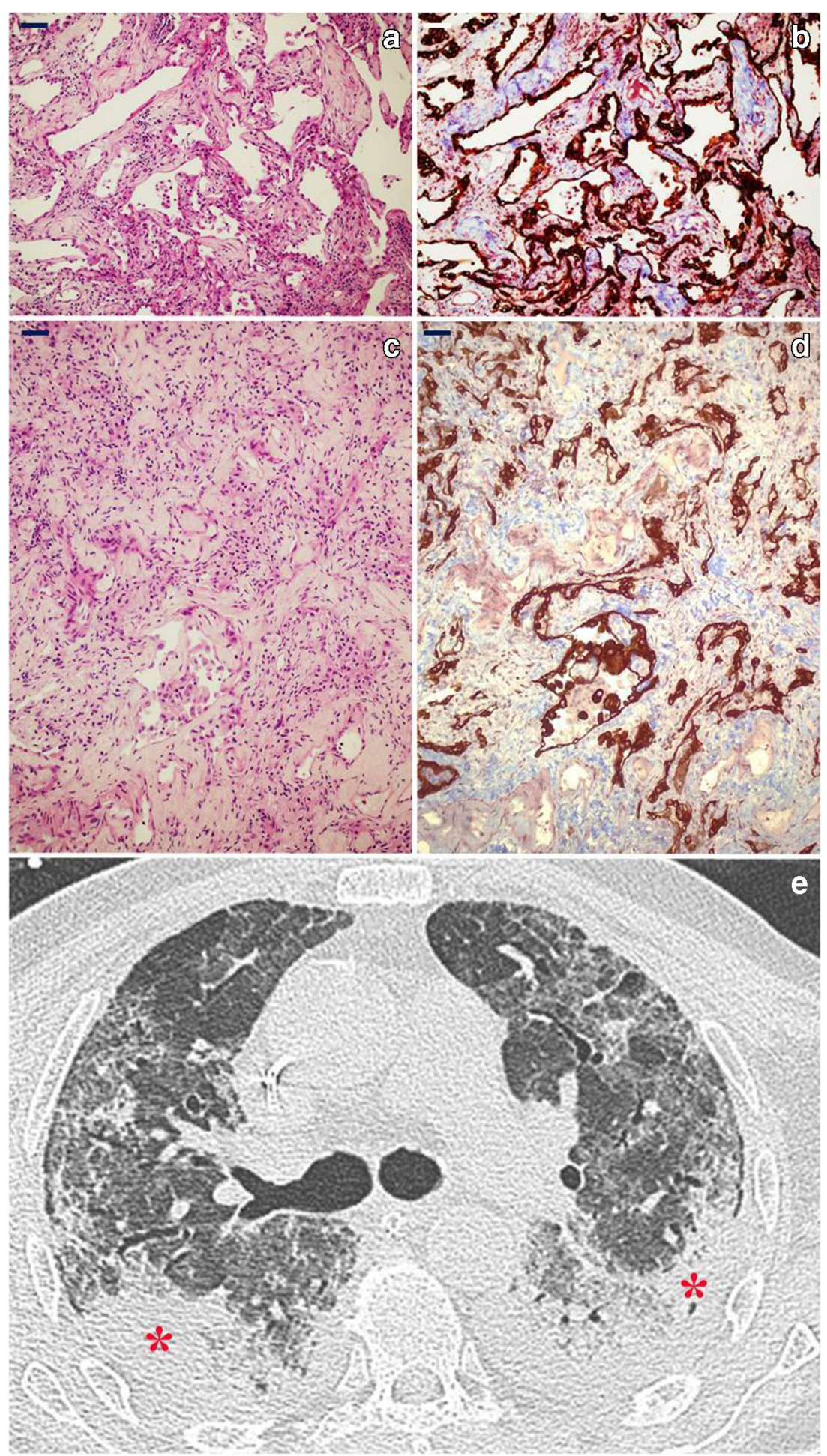

patients with longer spans of illness exhibit more interstitial fibrosis than those with shorter disease course. Furthermore, fibrosis was found even though all patients received antiinflammatory treatment during the course of the disease. In particular, regarding patient 1 who showed a late/organizing fibrotic phase of DAD with micro-honeycombing, the parenchymal re-modelling finds no justification in previous pulmonary disease, as shown by a total body CT scan performed in 2013 following an accident, which revealed normal lungs; furthermore, the patient referred no respiratory symptoms whatsoever till the onset of COVID-19.

Immunohistochemistry for SARS-CoV-2 nucleocapsid protein also showed modification during disease progression as intense immunostaining was seen in early exudative phase 


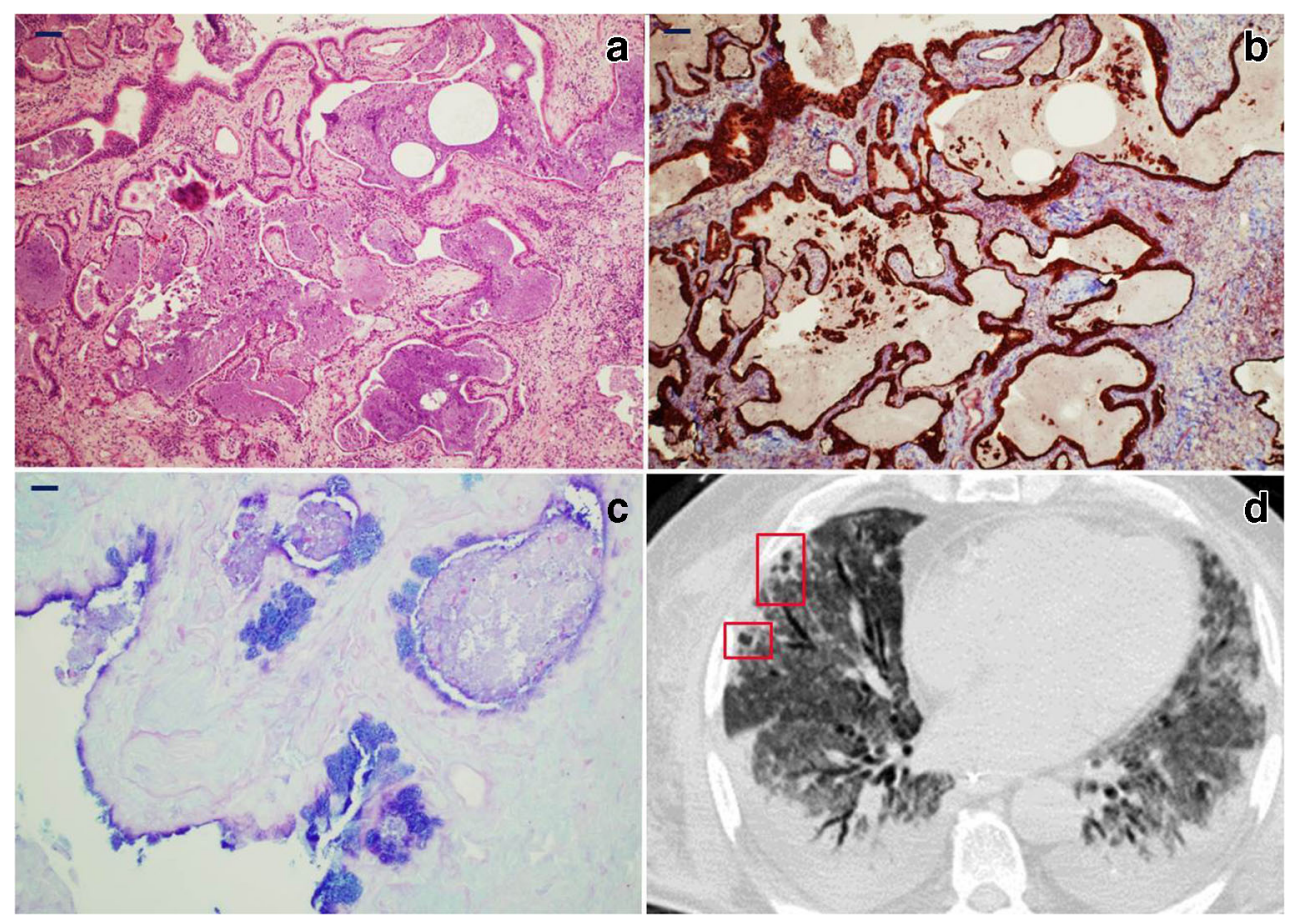

Fig. 5 Histology and radiology of micro-honeycombing pattern: a Complete re-modelling of parenchymal structure by fibrosis and mucinous filling of the alveolar spaces (H\&E, $\times 10$; scale bar $100 \mu \mathrm{m})$. b Mallory trichrome shows collagen deposition (light blue), and CK7 highlights diffuse bronchiolization of epithelial lining (brown) (CK7 immunoperoxidase with Mallory trichrome counterstain, $\times 10$; scale bar $100 \mu \mathrm{m})$. c Alcian blue/PAS stain highlights diffuse mucinous metaplasia

lesions, while little or no immunostaining was identified in proliferative and late/organizing fibrotic phases, similarly to findings in two recent studies [23, 31].

Much importance has been placed on vascular injury, endotheliitis and the hyper-coagulative state which seem to be important aspects of COVID-19 [11]. We identified platelet microthrombi (CD61+) in 4 patients to support this; patient 2 was also shown by imaging (echocardiogram positive) to have massive pulmonary thromboembolism. No large vessel thrombi, as identified in full post-mortems, were seen,

Fig. 6 Histogram showing relation between histologic phase and lung lobe involvement. The exudative phase is more represented in the upper lobes while the late phase prevails in the lower lobes of the epithelial lining (alcian blue/PAS, $\times 40$; scale bar $50 \mu \mathrm{m}$ ). d CT shows parenchymal diffuse GGO alterations with initial honeycombing pattern (subpleural clustered cystic air spaces, characterized by welldefined walls) in the middle lobe (red boxes); bilateral pleural effusion and mild consolidations in the posterior lower lobes, with bronchial enlargement, are also seen

probably due to sampling variability and/or the peripheral location of pmTBLCs.

A crucial aspect, which may have far-reaching therapeutic implications, is the inflammatory infiltrate in the lung parenchyma of COVID-19 patients. We have seen that macrophage accumulation is evident only in the early/mid-phases of disease, while numbers dwindle with increasing fibrosis. Macrophages, part of the innate immune response, are known to eliminate infectious agents and promote tissue repair through cytokine release. Interestingly, as suggested by Merad and Martin [32], subsets of macrophages in COVID-

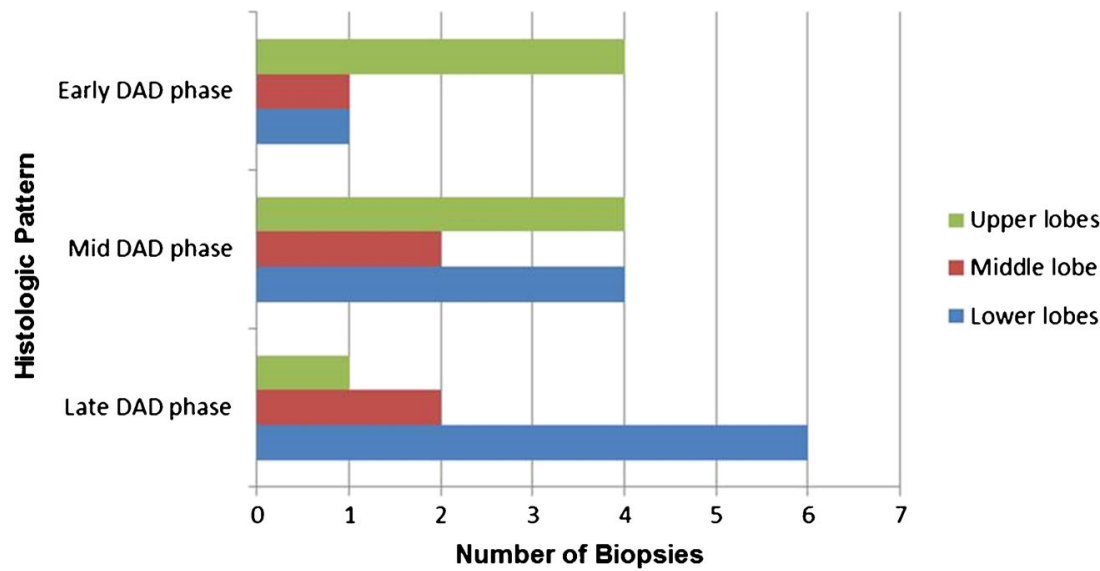


Fig. 7 SARS-CoV-2 nucleocapsid protein detection by immunohistochemistry. a Immunopositivity in the cytoplasm of bronchial cells and as a rim on their luminal border ( $x$ 60; scale bar $50 \mu \mathrm{m})$. b Immunopositivity in the cytoplasm of pneumocytes lining the alveolar space in early exudative phase DAD $(\times 100$; scale bar $25 \mu \mathrm{m})$. c Immunoreactivity of hyaline membranes in early exudative phase DAD $(\times 20$; scale bar 100 $\mu \mathrm{m})$. d) Immunopositive alveolar macrophages in exudative phase DAD $(\times 40$; scale bar $50 \mu \mathrm{m})$

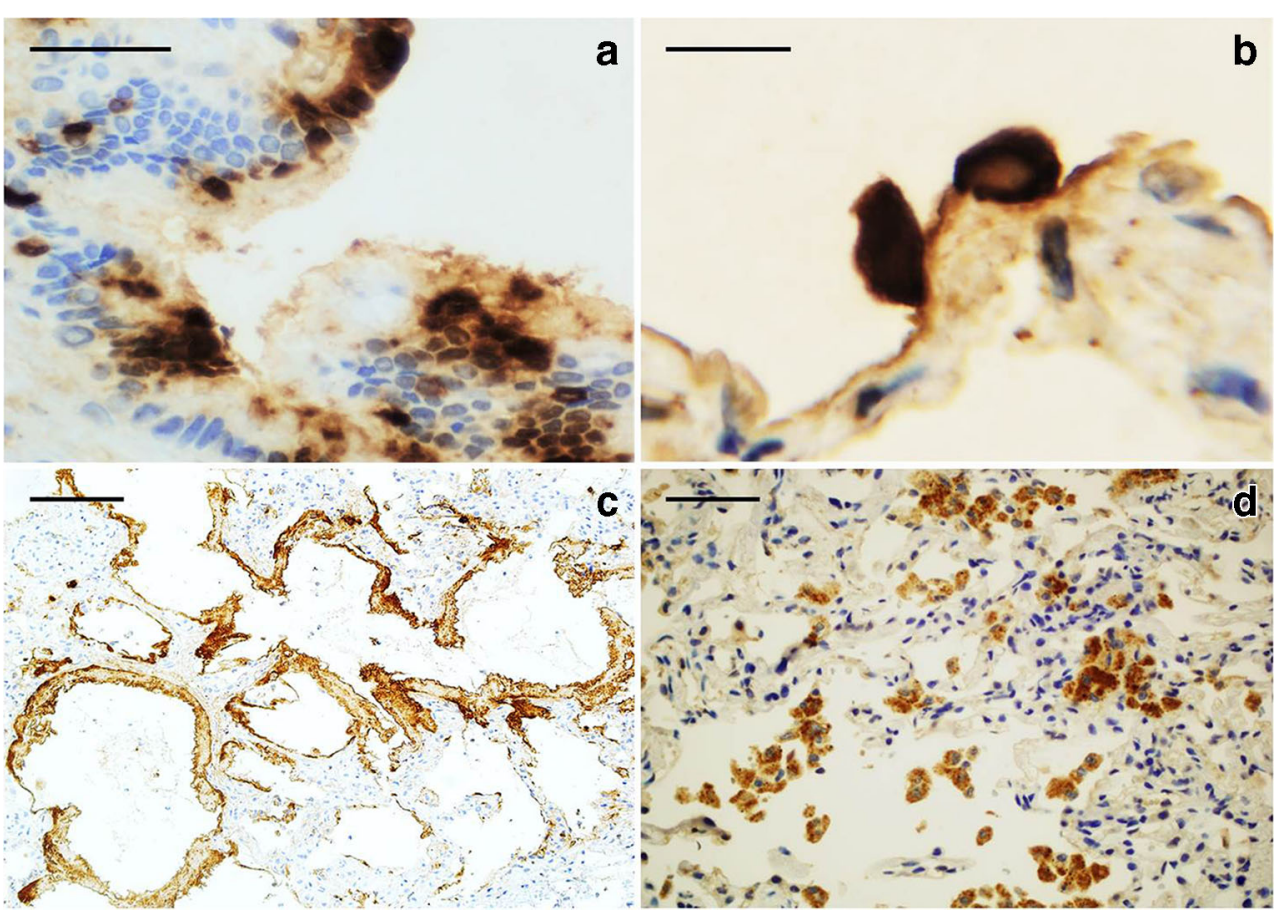

19 may express activated genes associated with tissue repair and this would explain the evolution to fibrosis which we have observed in our patients. It would prove useful, but difficult, to closely correlate disease timeline and extent of fibrosis, considering the many variables involved, including viral load, cytokine response and patient's variability.

CT scan findings have been extensively documented and prove useful for both diagnosing and following progression in
COVID-19 lung manifestations [33]. Histology correlates with various imaging patterns. Briefly summarizing, we found that crazy paving pattern at $\mathrm{CT}$ was associated with mid-phase DAD while the consolidation CT pattern was mainly correlated with late-phase DAD. Ground-glass opacities may be seen isolated in the early phases or as part of a more complex pattern in later progressive disease. Any discrepancies between histologic and CT findings may be partly explained

Table 3 Correlation between histologic patterns and CT features for each biopsy site (Spearman's Rho: $\mathrm{R}_{\mathrm{s}} 0 \cdot 8$ )

\begin{tabular}{|c|c|c|c|c|c|c|}
\hline & & \multicolumn{5}{|l|}{ CT features } \\
\hline & & Normal & Ground glass & Crazy paving & Consolidation & Honeycombing \\
\hline \multirow[t]{5}{*}{$\begin{array}{l}\text { Histologic } \\
\text { pattern }\end{array}$} & Normal & $\begin{array}{l}\text { Patient 6- } \\
\text { RLL/RML/LLL } \\
\text { Patient 8-RLL }\end{array}$ & & & & \\
\hline & Early-phase DAD & $\begin{array}{l}\text { Patient 8- } \\
\text { RML/LLL/LUL }\end{array}$ & $\begin{array}{l}\text { Patient 6- } \\
\text { RUL/LUL } \\
\text { Patient 8-RUL }\end{array}$ & & & \\
\hline & Mid-phase DAD & & $\begin{array}{l}\text { Patient 2-LUL } \\
\text { Patient 5- } \\
\text { RML }\end{array}$ & $\begin{array}{l}\text { Patient 2-LLL } \\
\text { Patient 3- } \\
\text { LLL/LUL } \\
\text { Patient 7- } \\
\text { RML/RUL/LUL }\end{array}$ & Patient 7-RLL/LLL & \\
\hline & $\begin{array}{l}\text { Late/organizing-phase } \\
\text { DAD }\end{array}$ & & $\begin{array}{l}\text { Patient 2-RML } \\
\text { Patient 5-LUL }\end{array}$ & & $\begin{array}{l}\text { Patient } 1-\mathrm{LLL} \\
\text { Patient 3-RLL } \\
\text { Patient 4-RLL } \\
\text { Patient 5-RLL/LLL }\end{array}$ & \\
\hline & Micro-honeycombing & & & & & $\begin{array}{l}\text { Patient 1- } \\
\text { RLL/RML }\end{array}$ \\
\hline
\end{tabular}

$R L L$ right lower lobe, $R M L$ right middle lobe, $R U L$ right upper lobe, $L L L$ left lower lobe, $L U L$ left upper lobe, $D A D$ diffuse alveolar damage

*For each biopsy site, one or two biopsies were available for evaluation depending on adequacy, for a total of 39 samples from 29 biopsy sites 
Fig. 8 Correlation between histologic and radiologic $C T$ patterns (see also Table 3). Early damage was found either in apparently healthy lung regions at imaging or associated with ground-glass opacities. Crazy paving was the most characteristic feature of the mid DAD phase, while consolidation and honeycombing were associated with the late-phase histologic changes

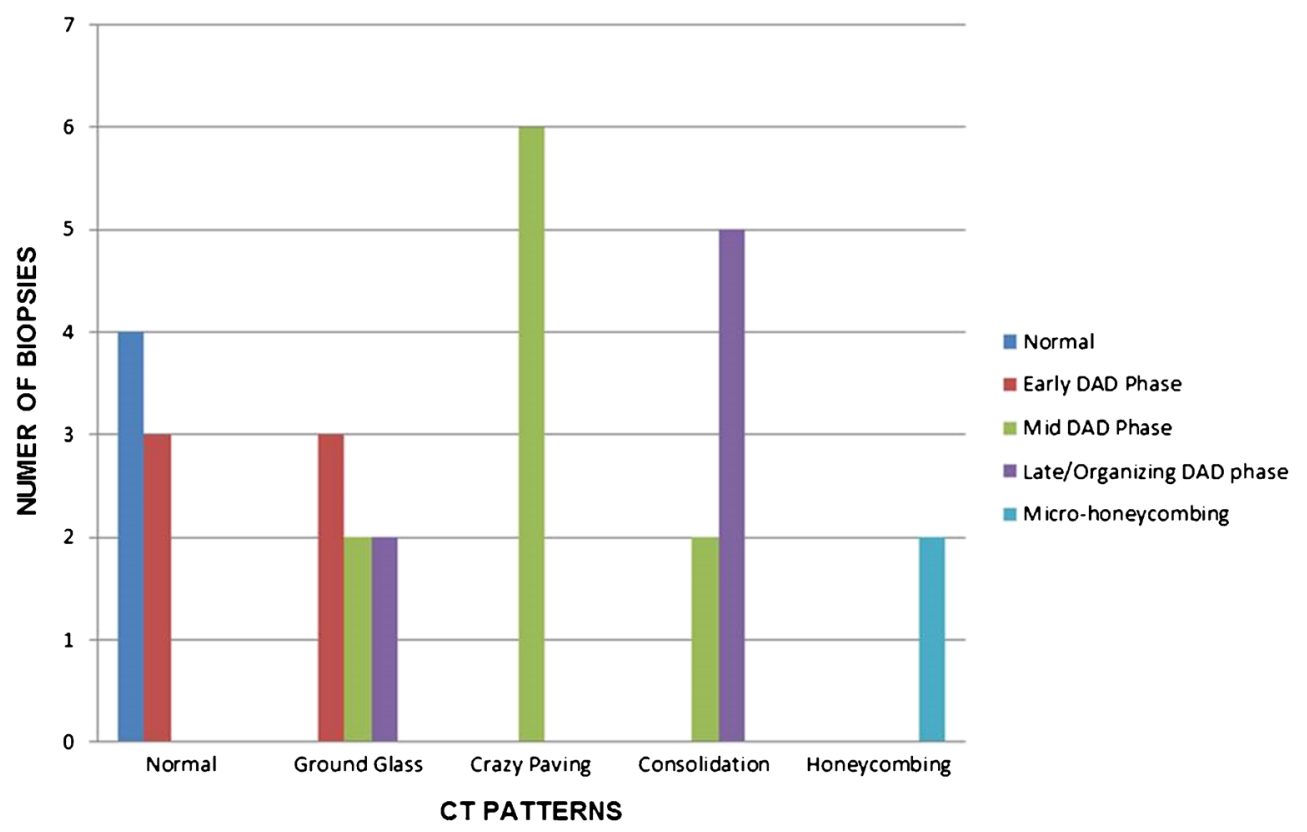

by lapse between CT scan and death (in some cases 10 days) or superimposed bronchopneumonia (patient 7 showed midphase DAD but had consolidated CT findings as a possible consequence of superimposed, diffuse, histologically proven, bronchopneumonia).

We may expect that an, as yet, unknown number of COVID-19 survivors who required mechanical ventilation for a long period of time might present lung function impairment with unresolved fibrotic interstitial lung disease [34]. SARS epidemic data show that, within the first year from acute illness, a relevant rate of survivors (15-20\%) showed reduced lung functional capacity [35]. Furthermore, a recent study with long-term follow-up demonstrated that, in patients with severe acute SARS related illness, lesions rapidly improved within the first year and then plateaued in the following 15 years with chronic CT lesions and lung function impairment [36]. In consideration of this, a complete and longterm follow-up, with functional studies, imaging and even cryobiopsies, could be necessary for COVID-19 patient management.

Limitations of this study which need to be addressed are the possibility of sampling variability and the inadequacy of many of the first samples due to the necessary learning curve. With regard to the former, biopsy sampling is clearly more limited if compared with full lung post-mortem evaluation, which collects greater information on the spatial distribution of lesions, and therefore, this should be taken into account. However, considering that TBLC are routinely performed for the diagnosis of interstitial lung disease, this itself validates the procedure, even with limitations. A further limitation of the study is the small number of procedures performed in a cohort of patients with a variety of demographic and clinical characteristics, as well as variable medical treatment.

In conclusion, COVID-19 lung injury is characterized by a diffuse alveolar damage histologic pattern with possible major fibrotic evolution in lungs of patients dying after a long period of mechanical ventilation. The knowledge of the histologic features which accompany the different phases of disease, and in particular with regard to fibrous progression, as well as the correlation between histology and CT patterns, constitutes a useful basis for interpreting the meaning of lesions that we may encounter in COVID-19 survivors as well as being the rational basis for the development of new treatments for which an accurate timing of lesions may be necessary.

Acknowledgements We wish to thank Simona Pigozzi and Monica Curto for the technical assistance and the next of kin of the deceased for their permission for post-mortem cryobiopsy execution.

Authors' contribution Emanuela Barisione performed the cryobiopsy procedures, designed the study and was part of the writing committee.

Federica Grillo evaluated the histology, performed analyses and was part of the writing committee.

Lorenzo Ball enrolled patients, collected clinical information and aided in cryobiopsy procedures and was part of the writing committee.

Rita Bianchi evaluated the histology and was part of the writing committee.

Marco Grosso collected clinical information and aided in cryobiopsy procedures and was part of the writing committee.

Patrizia Morbini provided the antibody directed against the nucleocapsid protein of SARS-CoV-2 and expertise in evaluation.

Nicolò Patroniti, Angelo Gratarola and Paolo Pelosi enrolled patients and were part of the writing committee.

Giovanni Orengo designed the study and oversaw quality assurance.

Marta Verda and Giuseppe Cittadini evaluated CT scans and were part of the writing committee. 
Luca Mastracci collected histologic samples, evaluated histology and performed iconographic documentation and was part of the writing committee.

Roberto Fiocca designed the study, evaluated the histology and was part of the writing committee.

All authors read, critically reviewed and approved the manuscript.

Funding Open access funding provided by Università degli Studi di Genova within the CRUI-CARE Agreement. Institutional financial support was provided to this study; funding played no significant role in study design, collection, analysis or data interpretation.

Data availability Data and material are available in local databases, upon request.

\section{Compliance with ethical standards}

Conflicts of interest All the authors declare no conflicts of interest.

\section{Code availability Not applicable.}

Open Access This article is licensed under a Creative Commons Attribution 4.0 International License, which permits use, sharing, adaptation, distribution and reproduction in any medium or format, as long as you give appropriate credit to the original author(s) and the source, provide a link to the Creative Commons licence, and indicate if changes were made. The images or other third party material in this article are included in the article's Creative Commons licence, unless indicated otherwise in a credit line to the material. If material is not included in the article's Creative Commons licence and your intended use is not permitted by statutory regulation or exceeds the permitted use, you will need to obtain permission directly from the copyright holder. To view a copy of this licence, visit http://creativecommons.org/licenses/by/4.0/.

\section{References}

1. Zhu N, Zhang D, Wang W, Li X, Yang B, Song J, Zhao X, Huang B, Shi W, Lu R, Niu P, Zhan F, Ma X, Wang D, Xu W, Wu G, Gao GF, Tan W, China Novel Coronavirus Investigating and Research Team (2020) A novel coronavirus from patients with pneumonia in China, 2019. N Engl J Med 382:727-733. https://doi.org/10.1056/ NEJMoa2001017

2. Huang C, Wang Y, Li X, Ren L, Zhao J, Hu Y, Zhang L, Fan G, Xu J, Gu X, Cheng Z, Yu T, Xia J, Wei Y, Wu W, Xie X, Yin W, Li H, Liu M, Xiao Y, Gao H, Guo L, Xie J, Wang G, Jiang R, Gao Z, Jin Q, Wang J, Cao B (2020) Clinical features of patients infected with 2019 novel coronavirus in Wuhan, China. Lancet 395:497-506. https://doi.org/10.1016/S0140-6736(20)30183-5

3. Wang D, Hu B, Hu C, Zhu F, Liu X, Zhang J, Wang B, Xiang H, Cheng Z, Xiong Y, Zhao Y, Li Y, Wang X, Peng Z (2020) Clinical characteristics of 138 hospitalized patients with 2019 novel coronavirus-infected pneumonia in Wuhan, China. JAMA 323: 1061-1069. https://doi.org/10.1001/jama.2020.1585

4. Grasselli G, Pesenti A, Cecconi M (2020) Critical care utilization for the COVID19 outbreak in Lombardy Italy: early experience and forecast during emergency response. Crit Care 24:175-1546. https://doi.org/10.1001/jama.2020.4031

5. Bao C, Liu X, Zhang H, Li Y, Liu J (2020) Coronavirus disease 2019 (COVID-19) CT findings: a systematic review and meta-analysis. J Am Coll Radiol 119:982-989. https://doi.org/10.1016/j.jacr. 2020.03.006
6. Sapino A, Facchetti F, Bonoldi E, Gianatti A, Barbareschi M (2020) The autopsy debate during the COVID-19 emergency: the Italian experience. Virchows Archiv 476:821-823. https://doi.org/ 10.1007/s00428-020-02828-2

7. Hanley B, Lucas SB, Youd E, Swift B, Osborn M (2020) Autopsy in suspected COVID-19 cases. J Clin Pathol 73:239-242. https:// doi.org/10.1136/jclinpath-2020-206522

8. Xu Z, Shi L, Wang Y, Zhang J, Huang L, Zhang C, Liu S, Zhu L, Tai Y, Bai C, Gao T, Song J, Xia P, Dong J, Zhao J, Wang FS (2020) Pathological findings of COVID-19 associated with acute respiratory distress syndrome. Lancet Respir Med 8:420-422. https://doi.org/10.1016/S2213-2600(20)30076-X

9. Tian S, Hu W, Niu L, Liu H, Xu H, Xiao SY (2020) Pulmonary pathology of early-phase 2019 novel coronavirus (COVID-19) pneumonia in two patients with lung cancer. J Thorac Oncol 15: 700-704. https://doi.org/10.1016/j.jtho.2020.02.010

10. Menter T, Haslbauer JD, Nienhold R, Savic S, Hopfer H, Deigendesch N, Frank S, Turek D, Willi N, Pargger H, Bassetti S, Leuppi JD, Cathomas G, Tolnay M, Mertz KD, Tzankov A (2020) Post-mortem examination of COVID19 patients reveals diffuse alveolar damage with severe capillary congestion and variegated findings of lungs and other organs suggesting vascular dysfunction. Histopathology. 77:198-209. https://doi.org/10.1111/his. 14134

11. Wichmann D, Sperhake JP, Lütgehetmann M, Steurer S, Edler C, Heinemann A, Heinrich F, Mushumba H, Kniep I, Schröder AS, Burdelski C, de Heer G, Nierhaus A, Frings D, Pfefferle S, Becker $\mathrm{H}$, Bredereke-Wiedling $\mathrm{H}$, de Weerth A, Paschen HR, Sheikhzadeh-Eggers S, Stang A, Schmiedel S, Bokemeyer C, Addo MM, Aepfelbacher M, Püschel K, Kluge S (2020) Autopsy findings and venous thromboembolism in patients with COVID-19: a prospective cohort study. Ann Intern Med. 173:268-277. https:// doi.org/10.7326/M20-2003

12. Carsana L, Sonzogni A, Nasr A, Rossi RS, Pellegrinelli A, Zerbi P, Rech R, Colombo R, Antinori S, Corbellino M, Galli M, Catena E, Tosoni A, Gianatti A, Nebuloni M (2020) Pulmonary post-mortem findings in a series of COVID-19 cases from northern Italy: a twocentre descriptive study. The Lancet Infectious Diseases 20:11351140. https://doi.org/10.1016/S1473-3099(20)30434-5

13. Liu J, Zheng X, Tong Q, Li W, Wang B, Sutter K, Trilling M, Lu M, Dittmer U, Yang D (2020) Overlapping and discrete aspects of the pathology and pathogenesis of the emerging human pathogenic coronaviruses SARS-CoV, MERS-CoV, and 2019-nCoV. J Med Virol 92:491-494. https://doi.org/10.1002/jmv.25709

14. Hwang DM, Chamberlain DW, Poutanen SM, Low DE, Asa SL, Butany J (2005) Pulmonary pathology of severe acute respiratory syndrome in Toronto. Mod Pathol 18:1-10. https://doi.org/10. 1038/modpathol.3800247

15. Nicholls JM, Poon LLM, Lee KC, Ng WF, Lai ST, Leung CY, Chu CM, Hui PK, Mak KL, Lim W, Yan KW, Chan KH, Tsang NC, Guan Y, Yuen KY, Peiris JS (2003) Lung pathology of fatal severe acute respiratory syndrome. Lancet 361:1773-1778. https://doi.org/ 10.1016/s0140-6736(03)13413-7

16. Ng DL, Al Hosani F, Keating MK, Gerber SI, Jones TL, Metcalfe MG, Tong S, Tao Y, Alami NN, Haynes LM, Mutei MA, AbdelWareth L, Uyeki TM, Swerdlow DL, Barakat M, Zaki SR (2016) Clinicopathologic, immunohistochemical, and ultrastructural findings of a fatal case of Middle East Respiratory Syndrome Coronavirus Infection in the United Arab Emirates. Am J Pathol 186:652-658. https://doi.org/10.1016/j.ajpath.2015.10.024

17. Barisione E, Salio M, Romagnoli M, Praticò A, Bargagli E, Corbetta L (2019) Competence in transbronchial cryobiopsy. Panminerva Medica 61:290-297. https://doi.org/10.23736/S00310808.18.03567-X

18. Hetzel J, Maldonado F, Ravaglia C, Wells AU, Colby TV, Tomassetti S, Ryu JH, Fruchter O, Piciucchi S, Dubini A, 
Cavazza A, Chilosi M, Sverzellati N, Valeyre D, Leduc D, Walsh SLF, Gasparini S, Hetzel M, Hagmeyer L, Haentschel M, Eberhardt R, Darwiche K, Yarmus LB, Torrego A, Krishna G, Shah PL, Annema JT, Herth FJF, Poletti V (2018) Tranbronchial cryobiopsy for the diagnosis of diffuse parenchymal lung disease: expert statement from the cryobiopsy working group on safety and utility and a call for standardization of the procedure. Respiration 95:188-200. https://doi.org/10.1159/000484055

19. Hansell DM, Bankier AA, MacMahon H, McLoud TC, Müller NL, Remy J (2008) Fleischner Society: glossary of terms for thoracic imaging. Radiology 246:697-722. https://doi.org/10.1148/radiol. 2462070712

20. Shi H, Han X, Jiang N, Cao Y, Alwalid O, Gu J, Fan Y, Zheng C (2020) Radiological findings from 81 patients with COVID-19 pneumonia in Wuhan, China: a descriptive study. Lancet Infect Dis 20:425-434. https://doi.org/10.1016/S1473-3099(20)30086-4

21. Mehrad M, Colby TV, Rossi G, Cavazza A (2020) Transbronchial cryobiopsy in the diagnosis of fibrotic interstitial lung disease. Arch Pathol Lab Med. https://doi.org/10.5858/arpa.2020-0007-RA

22. Ravaglia C, Rossi G, Tomassetti S, Dubini A, Piciucchi S, Chilosi M, Cavazza A, Bendstrup E, Kronborg-White SB, Folkersen B, Colella S, Madsen LB, Poletti V (2019) Report standardization in transbronchial lung cryobiopsy. Arch Pathol Lab Med 143:416417. https://doi.org/10.5858/arpa.2018-0438-LE

23. Sauter JL, Baine MK, Butnor KJ, Buonocore DJ, Chang JC, Jungbluth AA, Szabolcs MJ, Morjaria S, Mount SL, Rekhtman N, Selbs E, Sheng ZM, Xiao Y, Kleiner DE, Pittaluga S, Taubenberger JK, Rapkiewicz AV, Travis WD (2020) Insights into pathogenesis of fatal COVID-19 pneumonia from histopathology with immunohistochemical and viral RNA studies. Histopathology. https://doi.org/10.1111/his.14201

24. Thille AW, Esteban A, Fernández-Segoviano P, Rodriguez JM, Aramburu JA, Vargas-Errázuriz P, Martín-Pellicer A, Lorente JA, Frutos-Vivar F (2013) Chronology of histological lesions in acute respiratory distress syndrome with diffuse alveolar damage: a prospective cohort study of clinical autopsies. Lancet Respir Med 1: 395-401. https://doi.org/10.1016/S2213-2600(13)70053-5

25. Liu J, Babka AM, Kearney BJ, Radoshitzky SR, Kuhn JH, Zeng X (2020) Molecular detection of SARS-CoV-2 in formalin-fixed, paraffin-embedded specimens. JCI Insight 18(5):139042. https:// doi.org/10.1172/jci.insight.139042

26. Carnevale S, Beretta P, Morbini P (2020) Direct endothelial damage and vasculitis due to SARS-CoV-2 in small bowel submucosa of COVID-19 patient with diarrhea. J Med Virol 3;10.1002/ jmv.26119

27. Varga Z, Flammer AJ, Steiger P, Haberecker M, Andermatt R, Zinkernagel AS, Mehra MR, Schuepbach RA, Ruschitzka F,
Moch H (2020) Endothelial cell infection and endotheliitis in COVID-19. Lancet 395:1417-1418. https://doi.org/10.1016/ S0140-6736(20)30937-5

28. Ackermann M, Verleden SE, Kuehnel M, Haverich A, Welte T, Laenger F, Vanstapel A, Werlein C, Stark H, Tzankov A, Li WW, Li VW, Mentzer SJ, Jonigk D (2020) Pulmonary vascular endothelialitis, thrombosis, and angiogenesis in Covid-19. N Engl J Med. 383:120-128. https://doi.org/10.1056/NEJMoa2015432

29. Schaller T, Hirschbühl K, Burkhardt K, Braun G, Trepel M, Märkl B, Claus R (2020) Postmortem examination of patients with COVID-19. JAMA 323:2518-2520. https://doi.org/10.1001/jama. 2020.8907

30. Dolhnikoff M, Duarte-Neto AN, de Almeida Monteiro RA, Ferraz da Silva LF, Pierre de Oliveira E, Nascimento Saldiva PH, Mauad T, Marcia Negri E (2020) Pathological evidence of pulmonary thrombotic phenomena in severe COVID-19. J Thromb Haemost 18:1517-1519. https://doi.org/10.1111/jth.14844

31. Schaefer IM, Padera RF, Solomon IH, Kanjilal S, Hammer MM, Hornick JL, Sholl LM (2020) In situ detection of SARS-CoV-2 in lungs and airways of patients with COVID-19. Mod Pathol:1-11. https://doi.org/10.1038/s41379-020-0595-z

32. Merad M, Martin JC (2020) Pathological inflammation in patients with COVID-19: a key role for monocytes and macrophages. Nat Rev Immunol 20:355-362. https://doi.org/10.1038/s41577-0200331-4

33. Ye Z, Zhang Y, Wang Y, Huang Z, Song B (2020) Chest CT manifestations of new coronavirus disease 2019 (COVID-19): a pictorial review. Eur Radiol 30:4381-4389. https://doi.org/10. 1007/s00330-020-06801-0

34. George PM, Wells AU, Jenkins RG (2020) Pulmonary fibrosis and COVID-19: the potential role for antifibrotic therapy. Lancet Respir Med. 8:807-815. https://doi.org/10.1016/S2213-2600(20)30225-3

35. Xie L, Liu Y, Xiao Y, Tian Q, Fan B, Zhao H, Chen W (2005) Follow-up study on pulmonary function and lung radiographic changes in rehabilitating severe acute respiratory syndrome patients after discharge. Chest 127:2119-2124. https://doi.org/10.1378/ chest.127.6.2119

36. Zhang P, Li J, Liu H, Han N, Ju J, Kou Y, Chen L, Jiang M, Pan F, Zheng Y, Gao Z, Jiang B (2020) Long-term bone and lung consequences associated with hospital-acquired severe acute respiratory syndrome: a 15-year follow-up from a prospective cohort study. Bone Res. 8. https://doi.org/10.1038/s41413-020-0084-5

Publisher's note Springer Nature remains neutral with regard to jurisdictional claims in published maps and institutional affiliations. 